\title{
A Smart Telecare System at Digital Home: Perceived Usefulness, Satisfaction, and Expectations for Healthcare Professionals
}

\author{
Laura Vadillo, ${ }^{1}$ María Luisa Martín-Ruiz, ${ }^{1}$ Iván Pau, \\ Rafael Conde, ${ }^{1}$ and Miguel Ángel Valero ${ }^{1,2}$ \\ ${ }^{1}$ Telematics Systems for Information and Knowledge Society Research Group, Telematics and Electronics Department, \\ Universidad Politécnica de Madrid, Carretera de Valencia, Km 7, Madrid, Spain \\ ${ }^{2}$ Centro de Referencia Estatal de Autonomía Personal y Ayudas Técnicas (CEAPAT), \\ Institute for Elderly and Social Services (IMSERSO), Ministry of Health, Social Services and Equality, C/Los Extremeños 1, \\ Madrid, Spain \\ Correspondence should be addressed to María Luisa Martín-Ruiz; marisam@diatel.upm.es
}

Received 2 February 2017; Revised 11 May 2017; Accepted 4 July 2017; Published 3 August 2017

Academic Editor: Bruno Andò

Copyright ( 92017 Laura Vadillo et al. This is an open access article distributed under the Creative Commons Attribution License, which permits unrestricted use, distribution, and reproduction in any medium, provided the original work is properly cited.

Sensors, combined with intelligent systems, can enhance the quality of the Telecare services deployed at home, improving the capability for detection of risk situations and the users care. However, there are no specific studies that evaluate this kind of Telecare systems by professionals that work in a Telecare center. This paper shows the results of an assessment of the current satisfaction and future expectations of the Telecare professionals when using advanced Telecare solutions deployed at home. The study has been conducted through structured interviews with 24 Telecare experts working in the Telecare center of the Spanish Red Cross for attending alarm calls for elderly people. The interviews had the support of the TALISMAN Telecare system that is a next-generation Telecare service deployed in the accessible digital home of Universidad Politécnica de Madrid. All participants showed overall satisfaction with TALISMAN and their intention to use it. Results showed that perceived usefulness is an important influencing factor to the intention to use it and the Quality of the Information is a key factor in the perceived usefulness. TALISMAN, as an example of a next-generation Telecare system, is seen as a tool with high potential for improving the care of elderly people at home.

\section{Introduction}

The population pyramid has changed in the last years. According to the United Nations, the number of an ageing population is projected to grow to more than 2 billion by 2050 [1]. This growth has important economic and social consequences. An ageing population demands new efficient strategies in the health service provision to enable the growing health needs arising from the aging of the population to be effectively solved.

Advances in sensors and home automation technologies combined with proper reasoning systems can offer significant benefits enhancing the local and remote detection and management of risk situations for the inhabitant at home, one of the main aims of the Telecare systems [2-4]. However, the availability of the technology does not necessarily involve their use. The provision of effective Telecare services depends on a set of human factors in addition to purely technological factors [5]. User acceptance is a crucial factor for the successful implementation of a new technology [6], including final users, healthcare professionals, and healthcare providers.

Some studies have been developed to understand the acceptance of these technologies by patients or elderly people [7-10]. Although acceptance of information technologies in the telehealth/Telecare field has been an important issue in the last years, it is relatively unknown what factors affect the acceptance by Telecare professionals of a health care telemonitoring system at smart home [11].

Telecare professionals are pivotal in the process of adoption of new Telecare solutions. However, studies carried out 


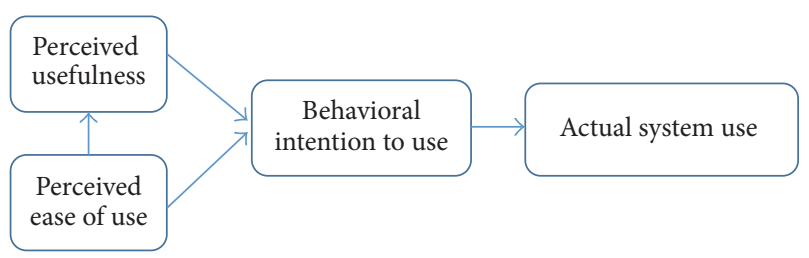

FIgURE 1: Technology acceptance model (TAM) [39].

in the health field are more centered in users or health professional satisfaction with telemonitoring or telemedicine systems [11-13]. Other works analyze factors that have influence on the successful implementation of technology for ageing people at home or for healthcare professionals [14, 15].

There are also studies which analyze the key factors influencing the intention of adoption for Telecare services [16, 17]. However, these studies are focused on an organizationenvironment perspective, skipping the operator point of view. On the other hand, there are different works focused on factors influencing adoption of home Telecare solutions by elderly using traditional Telecare systems. Nevertheless, these studies do not analyze a smart Telecare system using sensors to detect risk situations $[18,19]$.

Finally, there are other studies that analyze quality attributes and barriers to the adoption of Telecare solutions based on the smart home concept, but they are usually centered in administrative and technical factors with a human factor perspective, omitting the Telecare problematic and the Telecare professionals' opinions [20,21].

This study is the first to evaluate the satisfaction, expectations, and needs of Telecare professional working in a Telecare center. Results obtained in this study are relevant to knowing key elements that should be considered to implement the next generation of Telecare systems at home.

This paper presents a study oriented to understand the satisfaction and expectations of Telecare professionals with advanced Telecare systems. For this study development, professionals have been trained with a next-generation Telecare system called TALISMAN. TALISMAN is a context aware Telecare system developed by the TSIC (Telematics Systems for the Information and Knowledge Society), a research group of the Universidad Politécnica de Madrid.

\section{Background}

One of the cornerstones of the research is the selection of the accepted model. Several acceptance models applied in the healthcare field were evaluated.

The technology acceptance model (TAM) [22] is probably the most recognized, used, and validated model to measure and explain the factors that have influence on the acceptance of technology. Many other models are based on TAM [12, 23, 24]. This model (see Figure 1) takes the perceived usefulness (PU) and perceived ease of use (PEOU) as key factors to define the behavioral intention (BI) to using a system [22].

TAM has been validated in many scenarios and used as a good predictive model for defining the intention to be used by healthcare professionals [13, 25]. However, significant studies have suggested that TAM should integrate other factors in its acceptance model such as the perception of the environment and social influence, facilitators, factors related to relationships with the patients, and the applicability or compatibility of technology with the current practices, routines, and standards [25-30]. Although some studies have removed the significance on subjective norm and image in professionals when deciding to adopt health care technologies [31], these factors have been included in the majority of technology acceptance models.

Another popular model to measure the user satisfaction is the information system (IS) success DeLone and McLean model $[32,33]$. This model does not include factors related to the organization and compatibility. However, it evaluates the user satisfaction in terms of satisfaction with the system (system quality), with the information (information provided by the system compared with information that the user needs), with the software and with the decision making. Yusof et al. [34] propose a more complete model, adopting the IS success model to evaluate factors that have influence in health information systems (HIS). They divide factors in three dimensions: human factors (system use and user satisfaction), organizational factors (structure and environment), and technology factors (system quality, information quality, and service quality). Yusof's model is a complete method to measure the satisfaction with a telemonitoring system, the information quality, and the general system quality.

\section{Methods}

3.1. TALISMAN: Advanced Telecare System. TALISMAN is a platform which collects and manages the environmental data of the user's home to detect risky situations for the inhabitant. TALISMAN can interact with home elements and can provide information for helping Telecare professionals to take more efficient and quickly decisions.

TALISMAN is currently deployed in the accessible digital home $(\mathrm{ADH})$ of the Universidad Politécnica de Madrid (UPM). ADH is a real home around $80 \mathrm{~m}^{2}$, formed by a hall, a living-room, an equipped kitchen, a bathroom, and one bedroom. TALISMAN includes a group of sensors deployed in the house and a central unit with a multiagent platform to manage the information collected by sensors. Figure 2 shows the different components of TALISMAN system.

First 5 images (see Figure 2) show rooms of the house with some sensor elements controlled by TALISMAN. The last 2 images include the CM15 controller (interface X10 for TALISMAN), a Raspberry that captures data and executes the TALISMAN reasoning, and a Telecare unit with MyLife X10 to collect data about Tunstall Telecare sensors $868 \mathrm{MHz}$ and traduce them at X10 signals.

The interaction with users and the decision making is based on intelligent agents able to infer knowledge based on a reasoning engine. The reasoning model used by the intelligent agents is formalized by an ontology based on OWL (Web Ontology Language). This ontology maps the information obtained by sensors with potential hazards. TALISMAN, through intelligence agents, infers the state at home and proposes actions oriented to solve the inferred problem. 


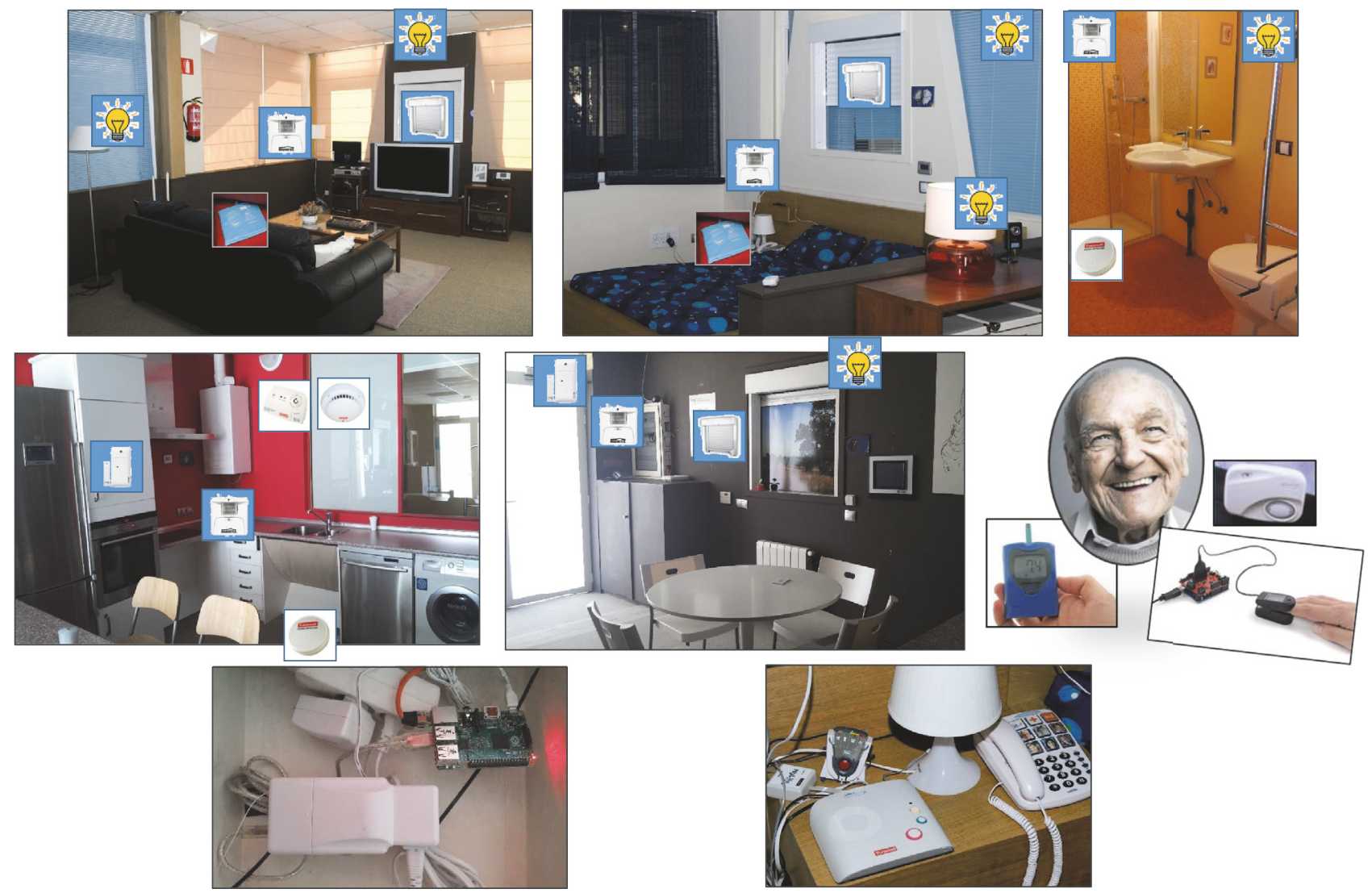

FIgURE 2: TALISMAN system installed at accessible digital home of UPM.

The information collected by the system can be displayed locally or remotely in real time. Figure 3 shows the monitor interface of TALISMAN. The interface provides the most relevant information about the inhabitant clinical profile, personal, and environmental sensors and finally the current action proposals based on the home and inhabitant situation.

One of the main advantages of the design of TALISMAN is that professionals can obtain a full report of the current state of the home in case any alarm is fired. This information, in properly managed, can lead to a more accurate response to the real situation.

3.2. Study Context. The study was conducted through a questionnaire to Telecare professionals after using the TALISMAN system. The questionnaire was designed to measure the expectations and satisfaction of the professionals related to the use of TALISMAN and its comparison with the current system deployed in the Spanish Red Cross Telecare center. This questionnaire was validated by an equipment of sociologists who are specialists in methodology and research techniques and by members of the coordination, equipment of the attention center of the Spanish Red Cross.

The traditional Telecare system (TTS) used in the Spanish Red Cross is based on a pendant and a home unit. Home unit is a device with a button connected to the home phone. This device allows establishing oral communication with a Telecare professional of the Telecare center when user presses the button. The pendant is a small device, which can be worn as a necklace, and the user can always wear it, even while in the shower or during sleep. Pendant includes a button that the user can press in any moment inside home to ask for help at Telecare center.

The TALISMAN system is shown to the staff to offer them a more advanced version of Telecare. It is a real instrument that they can use to observe the possibilities that these systems can offer in comparison with the traditional Telecare. Table 1 shows an objective comparison about TTS and TALISMAN.

The TALISMAN system characteristics were exposed to the Red Cross Telecare professionals. They could observe the system behavior and their capabilities to use the interface of the system (showed in Figure 3) and test how the system would react with different sensors states possibilities chosen by them.

The questionnaire was developed following the original TAM model, including other relevant factors provided by acceptance theories of UTAUT, DeLone and McLean and Yusof models. User satisfaction was measured by a selfdeveloped 24-item user satisfaction questionnaire in terms of PU, PEOU, system quality, information quality, compatibility, facilitating conditions, and intention to use. Table 2 lists the group of factors analyzed in this research and definitions. The questionnaire results (shown in Table 3 ) are based on this list of factors and include all unopened questions. 


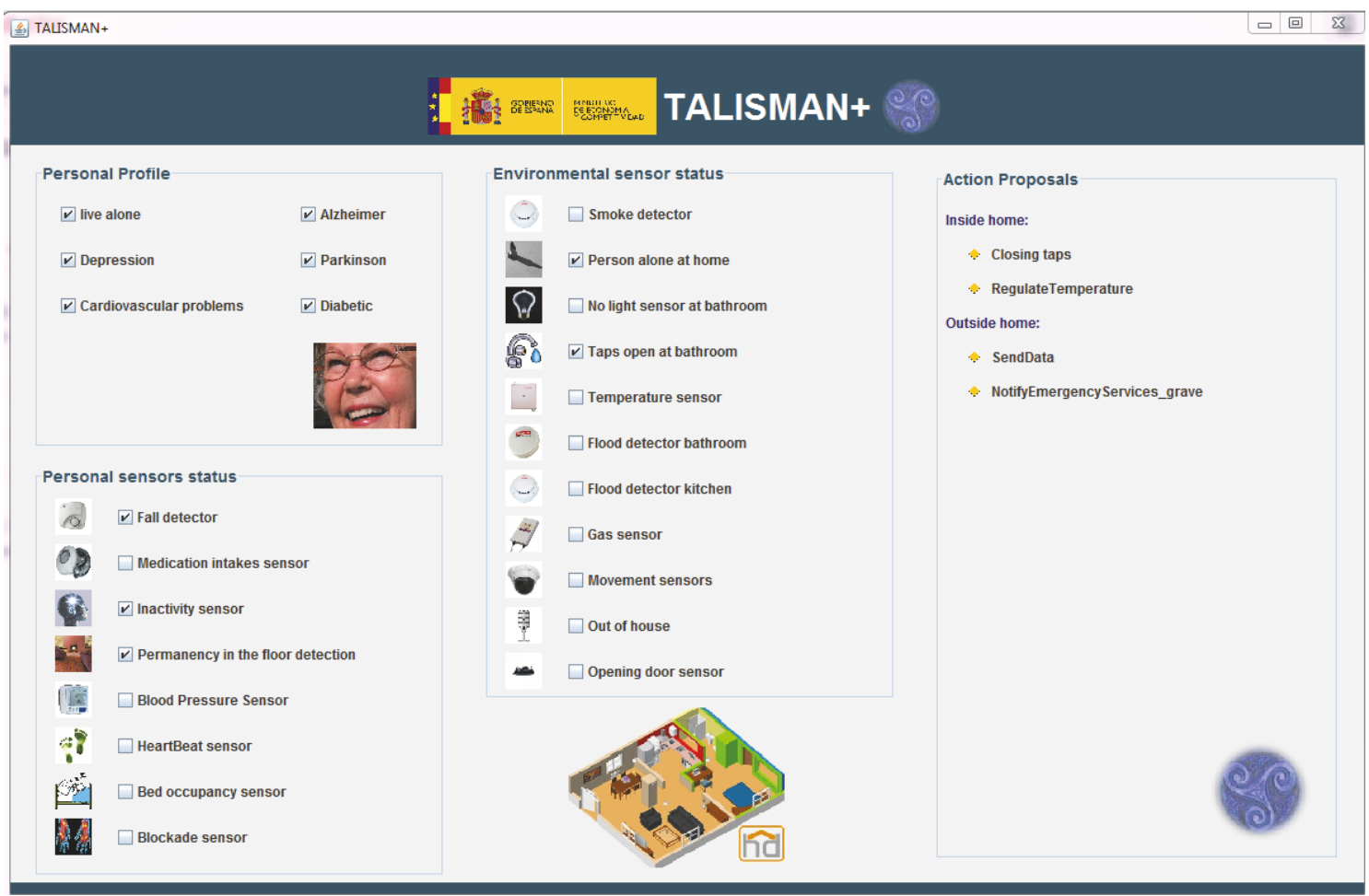

FIGURE 3: Complete interface of the TALISMAN system for a user's house.

In a total of 15 questions, responses have been rated on a five-point Likert scale anchored at strongly agree and strongly disagree. The questionnaire also includes four questions that can be answered with yes or no that need a positioning of the interviewee. Moreover, the questionnaire contains five open-ended questions to identify the user's perception of the Telecare system and the opinion about the lack of relevant information or the data representation. Information about age, years of experience, and specialty of studies of the interviewee was also collected.

The interviews were performed individually following the questionnaire design. The answers were recorded digitally for their subsequent analysis. In addition, interviewees' comments were collected during the questionnaire to complete and justify the results.

\section{Results}

The study was conducted during the months of March and April 2015 with 24 workers, $40 \%$ of the total, of the Telecare center of the Spanish Red Cross. All the participants had experience, between 10 months and 10 years, as Telecare professionals in Telecare centers. A total of 5 men and 19 women were interviewed and the average age was 43 years. The academic training was diverse: psychologists, social workers, teachers, and professional training mostly.

Table 3 presents the information related to the questionnaire and the answers collected from the Telecare professionals. The questionnaire has been designed to obtain indicators for the factors shown in Table 2. As previously commented, each indicator is evaluated through several questions summing up 19 measurable questions. Fifteen of the questions are rated on a five-point Likert scale: strongly agree labeled as "a," agree as "b," indifferent as "c," disagree as "d," and strongly disagree as "e." The remaining four are yes/no questions.

To visualize the evaluation of each indicator, Table 3 shows the mode, median, quartile 3 , and percentiles 80,90 , 95 , and 99 of each descriptive question analyzed in the questionnaire. The value of the percentiles has been calculated scoring each label with a numerical value (from "a" $=4$ to " $\mathrm{e} "=0)$. In the case of the statistical mode, its percentage is also provided with respect to all possible answers for that question (mode "a" with an associated percentage of 70,80\% means than the most frequent answer to that question was "a" having the $70,80 \%$ of all answers).

4.1. Perceived Ease of Use. Usability and presentation of data have a significant influence on the quality of the service. According to the professionals, the interface is understandable and its use does not require excessive effort. However, professionals add more valuable information in this case. Several participants stated that the TALISMAN interfaces are inefficient, demanding more attention and time than the current system in use in Red Cross. These participants suggest that this issue can be solved with an interface with the most important information highlighted alone at the top of the screen. This way the professional would not waste time 
TABLE 1: TTS and TALISMAN comparison.

\begin{tabular}{lll}
\hline & TTS & TALISMAN \\
\hline $\begin{array}{l}\text { Components } \\
\text { Home unit + pendant }\end{array}$ & $\begin{array}{l}\text { It also includes presence, smoke, dioxide carbon and flood } \\
\text { detectors, fall detector, bed and chair occupancy sensors, } \\
\text { contact sensors, glucometer, electrocardiogram, pulse and } \\
\text { oxygen, movement, activity, pulse, body temperature and } \\
\text { airflow sensors, and a processing and reasoning device }\end{array}$ \\
$\begin{array}{l}\text { Way to notify a } \\
\text { possible problem for } \\
\text { the user }\end{array}$ & Press the button & $\begin{array}{l}\text { It includes environment detection through sensors and } \\
\text { reasoning over collected data }\end{array}$ \\
\hline $\begin{array}{l}\text { Quantity of } \\
\text { information about a } \\
\text { dangerous situation }\end{array}$ & $\begin{array}{l}\text { Information obtained through } \\
\text { communication with the user. If the } \\
\text { user is not near to the home unit or is } \\
\text { fainting, it is not possible to know the } \\
\text { situation's gravity }\end{array}$ & $\begin{array}{l}\text { With the TALISMAN system, it is possible to obtain data } \\
\text { collected from the environment. The Telecare center can } \\
\text { obtain information about place at home, environment } \\
\text { situation, and last activities carried out by the user }\end{array}$ \\
\hline $\begin{array}{l}\text { Possibility to detect } \\
\text { possible health risk }\end{array}$ & $\begin{array}{l}\text { Only by means of information } \\
\text { obtained through communication with } \\
\text { the user }\end{array}$ & $\begin{array}{l}\text { The TALISMAN system could include a history of daily life } \\
\text { activities and timelines. This register of facts could help to } \\
\text { detect a new health symptom (user waking up often at night, } \\
\text { problematic patters of sleeping, lack of alimentation, etc.) or } \\
\text { dangerous situations like staying too long in bedroom without } \\
\text { going out and so on }\end{array}$ \\
\hline
\end{tabular}

Possibility to interact with the house of the user in case of gas scape or flood, for It is not possible for the Telecare staff Telecare staff could stop some actuators at home through gas/water electrovalves, for example

example

Action proposals

when a risk situation None

occurs
TALISMAN can propose some actions to the Telecare staff, according to the detected situation searching for this information, improving the response time (acritical factor in emergencies).

\subsection{Perceived Usefulness and System Efficiency. Telemonitor-} ing is associated with the improvement of the user quality of life by increasing the patient involvement in her/his house. In addition, it improves the efficiency of the call center since professionals have a more precise understanding of the user state. Furthermore, participants show their opinions with the decision making process performed by TALISMAN. In summary, the contestants think that the TALISMAN system provides very important information to know the state of the user at home and to detect risk situation and to support an appropriated professional action. They are also satisfied with unsupervised decisions made by the system. They think that TALISMAN can be very useful to help to take important decisions for several situations. (1) When the user presses the Telecare button accidentally, in this moment, he/she is not close to Telecare unit and he/she does not hear the Red Cross call. The system offers information whether the user is moving into another room of the house or if he is using the kitchen and so on, and it cannot activate unnecessary services for this reason. (2) The system can detect potential risk situation to the person and it can directly call Telecare center without the user activation (if the user remains for too long on the floor and spends too many hours in bed and so on). (3) The system can control medication and the detection of previous symptoms of Alzheimer's or other diseases through environmental control. (4) In addition, for talking with the user, TALISMAN provides more information to manage better the alarm ("TALISMAN is a very important complement to improve the service, to detect possible risk of the person at home, and to help us make better decisions, for example, when the person does not answer").

Relating to the efficiency of the system, the professionals stated that TALISMAN can process information quickly. However, respondents are conscious that the system could have limitations in the detection. Although $41.66 \%$ of respondents strongly agree with the affirmation that "the system allows detecting the user state when she/he is asking for assistance," other respondents are more cautious in their response (25\% “agree," $12.5 \%$ "indifferent," and 16.66\% "disagree"). This variability can be justified through some comments provided by respondents: "TALISMAN can help to know the user state at home, but not $100 \%$ " or "to know exactly what happened, it is necessary to put cameras or to speak with the user or with another person."

4.3. Compatibility. Telecare professionals do not consider that there are major compatibility problems between the TALISMAN and the current Telecare system, proposing a future integration with the current TTS. In addition, they think that the current procedures can be properly adapted to the new functionalities and functions received from TALISMAN. However, participants insisted on the fact that "any system can replace oral communication with the user or their 


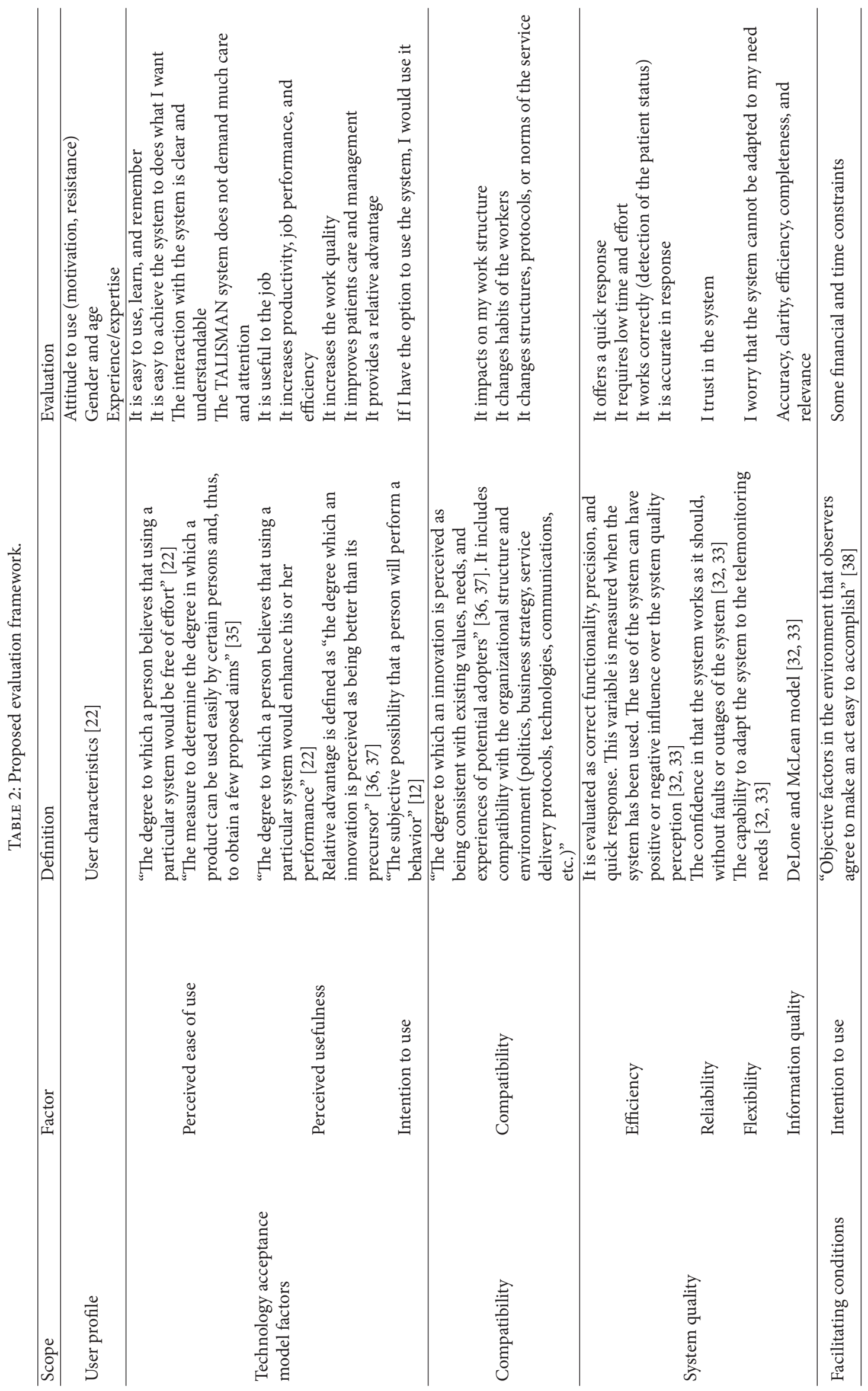




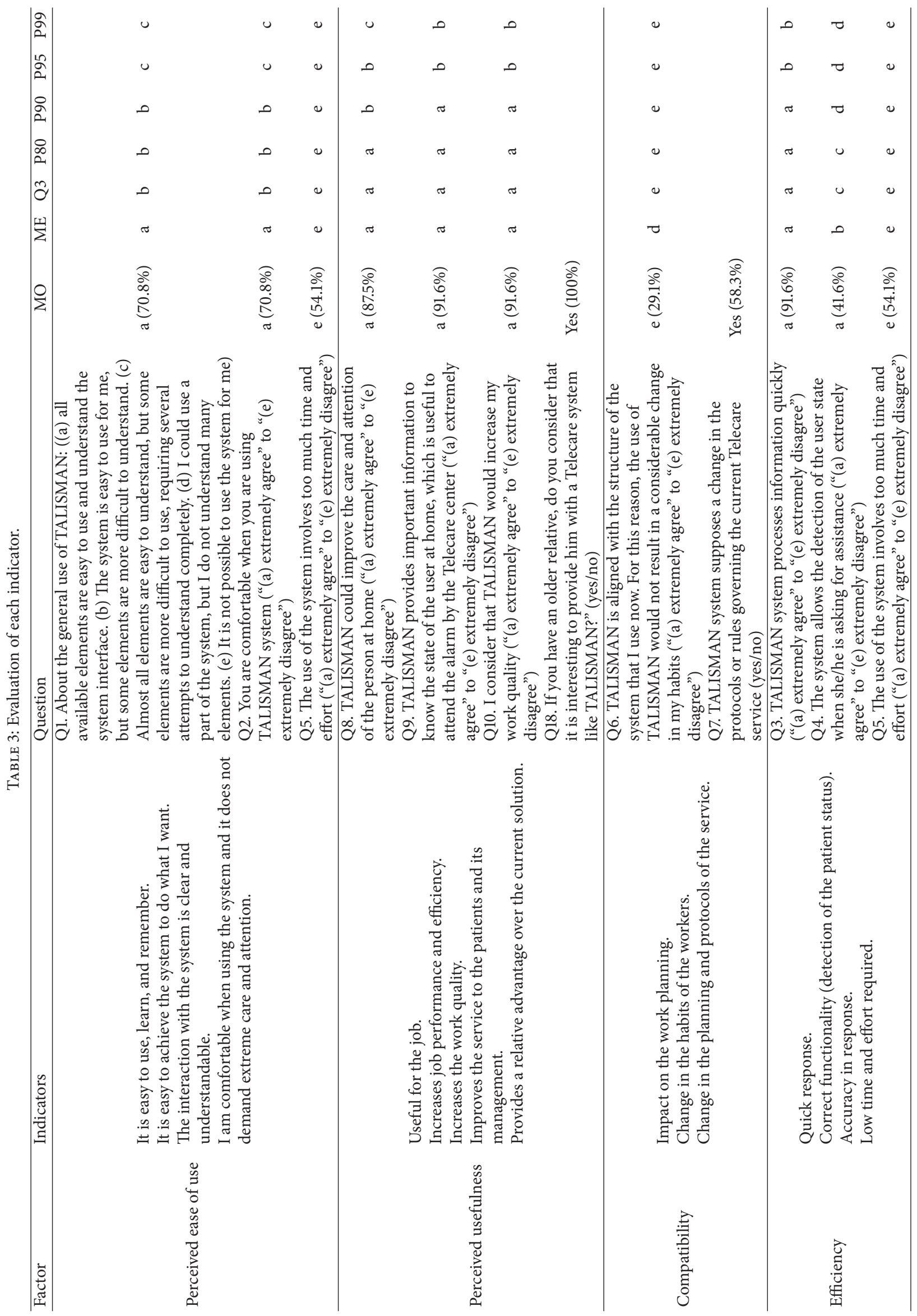




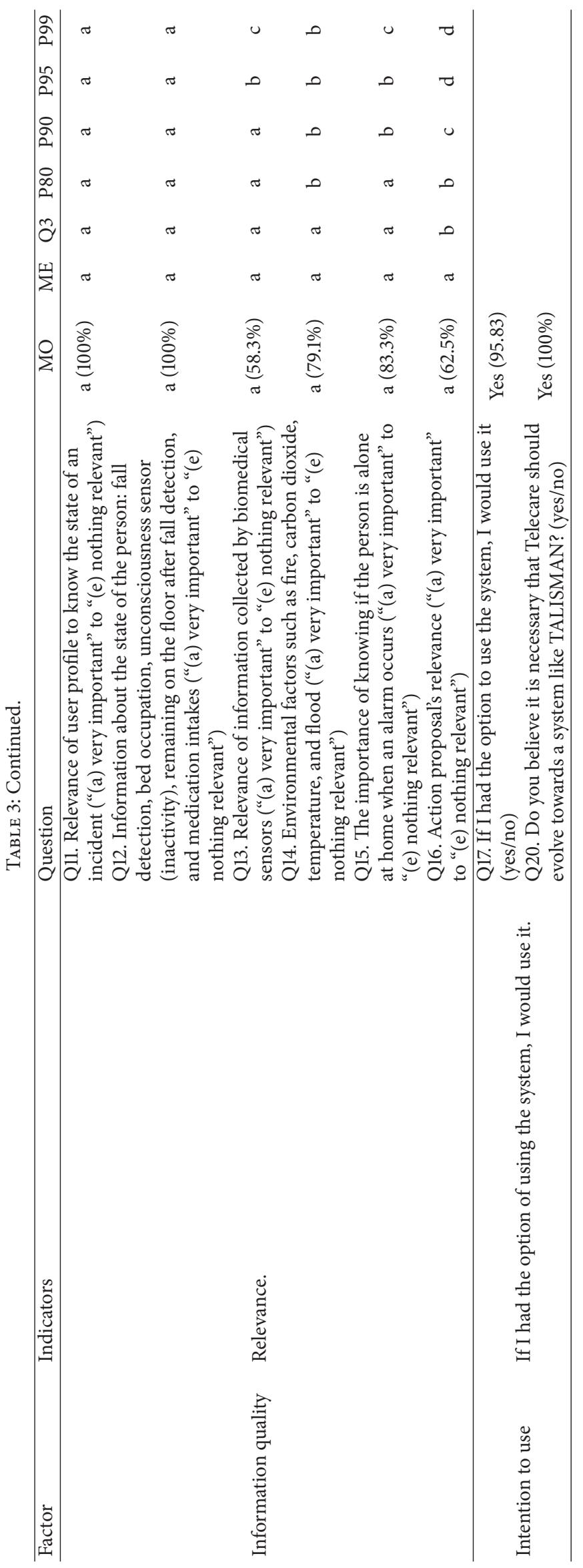




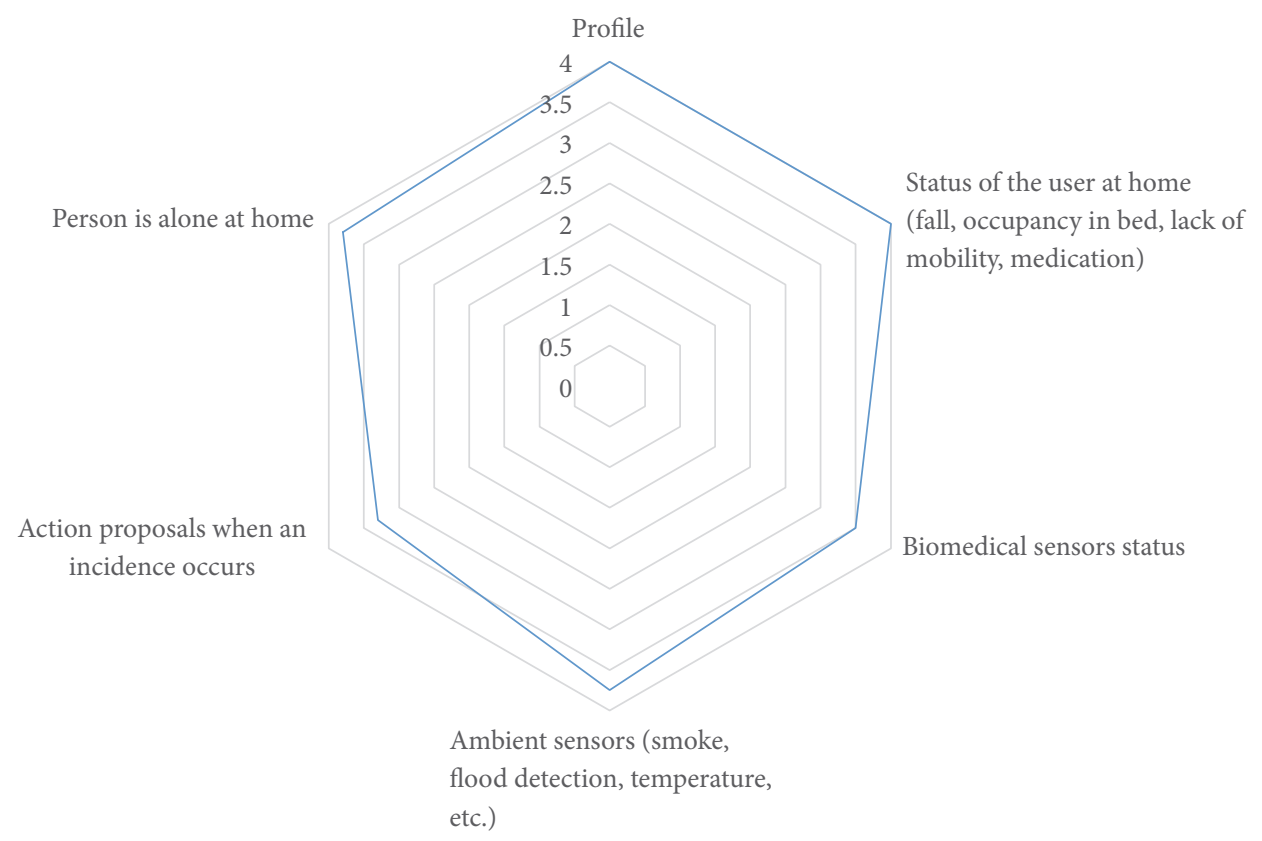

FIGURE 4: Relevance of information showed by the interface.

contacts, and whenever an alarm is received, Spanish Red Cross will try to talk with them." In this way, interviewees see TALISMAN like a system that can be configured and adapted to the person, with more possibilities to evolve.

4.4. Information Quality. This factor is a key point for the acceptance of TALISMAN system. There were six questions (Q11-Q16) related to the relevance of the information managed by the system: user profile, status of personal sensors, status of biomedical sensors, status of biomedical sensors, status of environmental sensors, and action proposals. Furthermore, there were two opened questions (Q23 and Q24) related to the quality of information, the lack or relevance of information, and the utility of the way representing the information.

Figure 4 shows a radar chart where all the variables are related to the importance of the different types of information defined in Q11-Q16. The numerical value of each variable corresponds to the mean of all the answers of the specific question (e.g., Q11 for profile) scoring the "a" label as 4 points, "b" as 3, "c" as 2, "b" as 1, and "e" label as 0 points.

As can we see in Figure 4, the information provided by biomedical sensors was considered less important than others because of lack of understanding ("we have not understood these measures") or small relevance to the final action ("this fact cannot have influence in the way of attend the alarm").

The most relevant information according to the professional is the one related to daily life actions of the patients: fall detection, bed occupation, inactivity, remaining on the floor, and medication intakes. They also considered very useful the environmental sensors (like fire, carbon monoxide, temperature, and flood). However, some of them showed their displeasure with the improper performance of some sensors ("some of these sensors switch on with the minimum detection, for example, when the person is cooking"). One of the most innovative features of the system, the action proposals, had good scores in satisfaction by a majority of the participants. Although some of the participants argued that it is a good idea, they know the protocols that they should follow, and this information is unnecessary. However, the majority of participants believe that it is a good idea always, both for new operators, that they are starting and all professionals to know what to do in any moment. Finally, the participants propose the use of all the profile information already included in the current system such as the user's telephone numbers and contacts and kind of health insurance.

4.4.1. Accuracy, Clarity, Efficiency, and Completeness of the Information. The questions 23 and 24 of the questionnaire were trying to measure the quality of information provided by the system, accuracy, clarity, and information that can lack or unnecessary and useless information to know the status of the person.

All participants agreed with the simplicity of the interface. However, they indicated that the information presented was not efficient for them. They point out that the interface showed too much information on the screen, and it was necessary to look at the screen to see clearly what was happening. They only proposed to show important information (only sensors that have been activated) highlighted at the top of the screen with icons, as we pointed out in "Perceived Ease of Use." Moreover, they considered important to show on the main screen the activated sensors together with the personal profile of the user (name, age, social security number, and contacts, among others) and action proposals by the TALISMAN system linked with the facility to call to contacts. For them, it is very inefficient to press several buttons to acquire this kind of information. Finally, some of them 
proposed to include an extra text box in order to complete the incidence with observations of Telecare center professionals.

When they were asked about "the completeness of the information and what elements they think that are missing and what are relevant or unnecessary," the majority of them answered that the system is very complete. However, professionals pointed to the necessity of having the actual personal profile that they collected in Spanish Cross Red integrated with the possibilities of TALISMAN and maintaining a history of advices and alerts.

For that, professionals proposed that the interface would include a button to extend information and to show previous events, which occurred at home, but using another screen.

Moreover, some of them proposed new sensors, like movement sensors in terraces or courtyard, and a personalization of no response time, depending on personal profile. Only two people believed that the use of cameras is necessary to know completely what is happening at the house. Another person suggested the importance of including new techniques, like GPS, to achieve amplified Telecare outside house.

4.5. Intention to Use and Expectation. Participants perceived TALISMAN as a solution to improve current Telecare. They concluded that TALISMAN would allow obtaining a great quantity of information to detect and manage incidents that traditional Telecare cannot. TALISMAN could be integrated with the current interface and protocols used by Spanish Red Cross so that the alarm call center can receive in each case a report with the complete situation with regard to what it is happening at home. Several participants stated the following intention to use: "current Telecare is good, but only is activated when the person presses the Telecare button." Others stated that "with a system like TALISMAN a world of possibilities can be open to improve the care of the people that use this service." Besides, they stated that "the current Telecare service has not changed in many years, and it is necessary to take advance of the new technologies to complete the service."

4.6. Price. Price is a possible barrier factor for using this service. Therefore, we asked about what price/month could be reasonable to pay for this service by user (Q19 of questionnaire). Around $30 \%$ set the price nearby $30 €$ (present cost of the service in Spain). Almost half of them considered that the price should be established according to the income of the person, taking into account that older people usually have very low income. $8.3 \%$ of responses established the price around 50-60€.

4.7. Advantages. Q21 was "what advantages you think that the system has?" All users refer to the safety for the user (better detection of risk situations), more valuable and objective information, and the speed to mobilize resources.

The factor flexibility repeatedly emerged during the interviews like advantage of the system. Interviewers see TALISMAN like a system that can be configured and adapted to the person, with more possibilities to evolve.
4.8. Barriers. When interviewers were asking about barriers to adopt the TALISMAN system (Q 22 of the questionnaire), problems that interviewers detected were as follows:

(i) Price (ageing people typically have low retirement pay)

(ii) Possible rejection of some users: there are users that are uncomfortable with many devices. The lack of information and unknown possibilities of TALISMAN and how it works could induce insecurity, lack of privacy, or control in certain users

(iii) Too many devices: therefore, TALISMAN would be perceived like being too intrusive

(iv) Configuration problems, by customizing to each user

(v) Possible technical problems (many false positives, no detection of a sensor, sensors reliability, battery failure, etc.)

4.9. Human Factor. A key factor to the success of any Telecare service is the human factor. Participant insisted on the usefulness of the TALISMAN but it never can replace the oral communication with the user or any of their contacts. "TALISMAN is a very important complement to improve the service, to detect possible risk of the person at home, and to help us to make decisions, for example, when the person does not answer."

\section{Limitations}

TALISMAN is a prototype currently running in a lab under controlled conditions. At the moment of writing this paper, it has not been integrated in the infrastructure of the Spanish Red Cross. This condition complicates the part of the evaluation of the service quality (reliability and efficiency of the service).

This study is part of a global study in which we have analyzed acceptance and satisfaction factors of other relevant stakeholders: final users, family members or informal caregivers, and Telecare technical installers.

\section{Conclusions}

Telecare professionals are pivotal actors in the provision of the Telecare service. The measure of professionals' satisfaction is a key issue in the successful deployment of the next-generation Telecare systems like TALISMAN.

This study points to factors having influence on the use and user satisfaction of smart telemonitoring systems. It is centered on the analysis of best practices, drivers, and barriers with the aim to improve the assistance provided and the professionals' work. These factors offer valuable information for the design and refinement of advanced Telecare systems of new generation. 


\section{Abbreviations}

ADH: Accessible digital home

PU: $\quad$ Perceived usefulness

PEOU: Perceived ease of use

BI: Behavioral intention to use

TTS: Traditional Telecare system

TAM: Technology acceptance model

UTAUT: Unified theory of acceptance and use of technology

HIS: $\quad$ Health information systems

UPM: Universidad Politécnica de Madrid.

\section{Data Access}

Data sharing is not applicable to this article as no datasets were generated or analyzed during the current study. This paper shows the results obtained through interviews guided by a questionnaire. The collected data were included and analyzed through excel document. The data can be accessed through contacting the authors.

\section{Conflicts of Interest}

The authors declare that they have no conflicts of interest.

\section{Authors' Contributions}

Laura Vadillo has participated in the study design, carried out the study with Telecare professionals, analyzed statistical data of the questionnaires, and participated in the manuscript redaction. María Luisa Martín-Ruiz has carried out the study with Telecare professionals, analyzed results, and participated in the manuscript redaction. Iván Pau has reviewed results from obtained data, helped to draft manuscript, and participated in the manuscript revision. Rafael Conde has participated in the study design and statistical data analysis. Miguel Ángel Valero is the main research and coordinator of this project and has participated in the study coordination, design, and revision. All authors read and approved the final manuscript.

\section{Acknowledgments}

The authors would like to thank Spanish Cross Red and their Telecare professionals that have participated in this study. This article is part of research conducted under EDUCERE (Ubiquitous Detection Ecosystem to Care and Early Stimulation for Children with Developmental Disorders) supported by the Ministry of Education and Science of Spain through the National Plan for R+D+I (Research, Development, and Innovation) (Project no. TIN2013-47803-C2-1-R).

\section{References}

[1] Population Ageing and Development, "Department of Economic and Social Affairs (DESA). Economic and Social Council (ECOSOC)," United Nations, 2012, http://social.un.org/ageingworking-group/documents/2012popageing.pdf.
[2] M. Alwan, S. Dalal, D. Mack et al., "Impact of monitoring technology in assisted living: Outcome pilot," IEEE Transactions on Information Technology in Biomedicine, vol. 10, no. 1, pp. 192198, 2006.

[3] P. Rashidi and A. Mihailidis, "A survey on ambient-assisted living tools for older adults," IEEE Journal of Biomedical and Health Informatics, vol. 17, no. 3, pp. 579-590, 2013.

[4] N. W. Averwater and D. C. Burchfield, "No place like home: telemonitoring can improve home care.," Healthcare financial management : journal of the Healthcare Financial Management Association, vol. 59, no. 4, pp. 46-52, 2005.

[5] T. ETSI, Human Factors (HF), 102 415, Telecare services.

[6] F. D. Davis, "Perceived usefulness, perceived ease of use, and user acceptance of information technology," MIS Quarterly, vol. 13, no. 3, pp. 46-53, 1989.

[7] S.-P. Su, C.-H. Tsai, and Y.-K. Chen, "Applying the Technology Acceptance Model to Explore Intention to Use Telecare System in Taiwan," in Proceedings of the 13th ACIS International Conference onSoftware Engineering, Artificial Intelligence, Networking and Parallel \& Distributed Computing (SNPD), pp. 353-356, 2012.

[8] B.-K. Chuang, C.-H. Tsai, H.-L. Hsieh, and T. Tumurtulga, "Applying health belief model to explore the adoption of telecare," in Proceedings of the 2013 IEEE/ACIS 12th International Conference on Computer and Information Science, ICIS 2013, pp. 269-272, jpn, June 2013.

[9] M. Rahimpour, N. H. Lovell, B. G. Celler, and J. McCormick, "Patients' perceptions of a home telecare system," International Journal of Medical Informatics, vol. 77, no. 7, pp. 486-498, 2008.

[10] J.-C. Huang, "Innovative health care delivery system-A questionnaire survey to evaluate the influence of behavioral factors on individuals' acceptance of telecare," Computers in Biology and Medicine, vol. 43, no. 4, pp. 281-286, 2013.

[11] C. Sicotte, G. Paré, S. Morin, J. Potvin, and M.-P. Moreault, "Effects of home telemonitoring to support improved care for chronic obstructive pulmonary diseases," Telemedicine and $e$ Health, vol. 17, no. 2, pp. 95-103, 2011.

[12] Y. Lee, K. A. Kozar, and K. R. T. Larsen, “The technology acceptance model: past, present, and future," Communications of the AIS, vol. 12, no. 50, pp. 752-780, 2003.

[13] R. J. Holden and B.-T. Karsh, "The Technology Acceptance Model: Its past and its future in health care," Journal of Biomedical Informatics, vol. 43, no. 1, pp. 159-172, 2010.

[14] S. T. M. Peek, E. J. M. Wouters, K. G. Luijkx, and H. J. M. Vrijhoef, "What it Takes to successfully implement technology for aging in place: Focus groups with stakeholders," Journal of Medical Internet Research, vol. 18, no. 5, article no. e98, 2016.

[15] M.-P. Gagnon, M. Desmartis, M. Labrecque et al., "Systematic review of factors influencing the adoption of information and communication technologies by healthcare professionals," Journal of Medical Systems, vol. 36, no. 1, pp. 241-277, 2012.

[16] C.-F. Liu, "Key factors influencing the intention of Telecare adoption: An institutional perspective," Telemedicine and $e$ Health, vol. 17, no. 4, pp. 288-293, 2011.

[17] D. Bouwhuis, L. Meesters, and A. Sponselee, "Models for the acceptance of tele-care solutions: Intention vs behaviour. Gerontechnology, 2012," http://gerontechnology.info/index.php/ journal/article/view/gt.2012.11.01.007.00.

[18] J. M. Peeters, A. J. E. De Veer, L. Van der Hoek, and A. L. Francke, "Factors influencing the adoption of home telecare by elderly or chronically ill people: a national survey," Journal of Clinical Nursing, vol. 21, no. 21-22, pp. 3183-3193, 2012. 
[19] I. v. Weersch, D. Ploegmakers, and R. Blok, Acceptance and Effectiveness of Telecare Services from the End-User Perspective, Eindhoven University of Technology, Eindhoven, The Netherlands.

[20] N. Balta-Ozkan, R. Davidson, M. Bicket, and L. Whitmarsh, "Social barriers to the adoption of smart homes," Energy Policy, vol. 63, pp. 363-374, 2013.

[21] T. Luor, H.-P. Lu, H. Yu, and Y. Lu, "Exploring the critical quality attributes and models of smart homes," Maturitas, vol. 82, no. 4, pp. 377-386, 2015.

[22] F. D. Davis, A technology acceptance model for empirically testing new end-user information systems: Theory and results, Sloan School of Management, Massachusetts Institute of Technology, Mass, USA, 1986.

[23] W. R. King and J. He, "A meta-analysis of the technology acceptance model," Information and management, vol. 43, no. 6, pp. 740-755, 2006.

[24] B. Szajna, "Empirical evaluation of the revised technology acceptance model," Management Science, vol. 42, no. 1, pp. 8592, 1996.

[25] P. Y. K. Chau and P. J. Hu, "Examining a model of information technology acceptance by individual professionals: An exploratory study," Journal of Management Information Systems, vol. 18, no. 4, pp. 191-229, 2002.

[26] M. P. Gagnon, E. Orruño, J. Asua, A. B. Abdeljelil, and J. Emparanza, "Using a modified technology acceptance model to evaluate healthcare professionals' adoption of a new telemonitoring system," Telemedicine and e-Health, vol. 18, no. 1, pp. 5459, 2011.

[27] P. Esmaeilzadeh, M. Sambasivan, N. Kumar, and H. Nezakhati, "Adoption of technology applications in healthcare: The influence of attitude toward knowledge sharing on technology acceptance in a hospital," Communications in Computer and Information Science, vol. 264, pp. 17-30, 2011.

[28] V. Venkatesh and F. D. Davis, "A theoretical extension of the technology acceptance model: four longitudinal field studies," Management Science, vol. 46, no. 2, pp. 186-204, 2000.

[29] J. Asua, E. Orruño, E. Reviriego, and M. P. Gagnon, "Healthcare professional acceptance of telemonitoring for chronic care patients in primary care," BMC Medical Informatics and Decision Making, vol. 12, no. 1, article no. 139, 2012.

[30] A. Kohnke, M. L. Cole, and R. Bush, "Incorporating UTAUT predictors for understanding home care patients' and clinician's acceptance of healthcare telemedicine equipment," Journal of Technology Management and Innovation, vol. 9, no. 2, pp. 2941, 2014.

[31] W. G. Chismar and S. Wiley-Patton, "Does the extended technology acceptance model apply to physicians," in Proceedings of the 36th Annual Hawaii International Conference on System Sciences, HICSS 2003, usa, January 2003.

[32] W. H. DeLone and E. R. McLean, "Information systems success: the quest for the dependent variable," Information Systems Research, vol. 3, no. 1, pp. 60-95, 1992.

[33] W. H. DeLone and E. R. McLean, "The DeLone and McLean model of information systems success: A ten-year update," Journal of Management Information Systems, vol. 19, no. 4, pp. 9-30, 2003.

[34] M. M. Yusof, J. Kuljis, A. Papazafeiropoulou, and L. K. Stergioulas, "An evaluation framework for Health Information Systems: human, organization and technology-fit factors (HOTfit)," International Journal of Medical Informatics, vol. 77, no. 6, pp. 386-398, 2008.
[35] J. Nielsen, "Usability Engineering. Interactive Technologies. Morgan Kaufmann Series in Interactive Technologies, 1996".

[36] E. A. Rogers, Diffusion of Innovation, The Free Press, NY, USA, 3rd edition, 1983.

[37] G. C. Moore and I. Benbasat, "Development of an instrument to measure the perceptions of adopting an information technology innovation," Information Systems Research, vol. 2, no. 3, pp. 192222, 1991.

[38] V. Venkatesh, M. G. Morris, G. B. Davis, and F. D. Davis, "User acceptance of information technology: toward a unified view," MIS Quarterly, vol. 27, no. 3, pp. 425-478, 2003.

[39] K. Arning and M. Ziefle, "Understanding age differences in PDA acceptance and performance," Computers in Human Behavior, vol. 23, no. 6, pp. 2904-2927, 2007. 


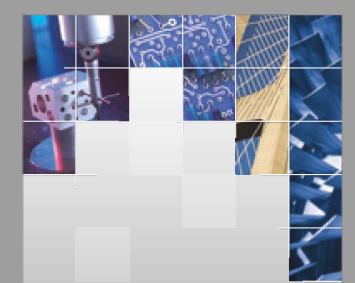

\section{Enfincering}
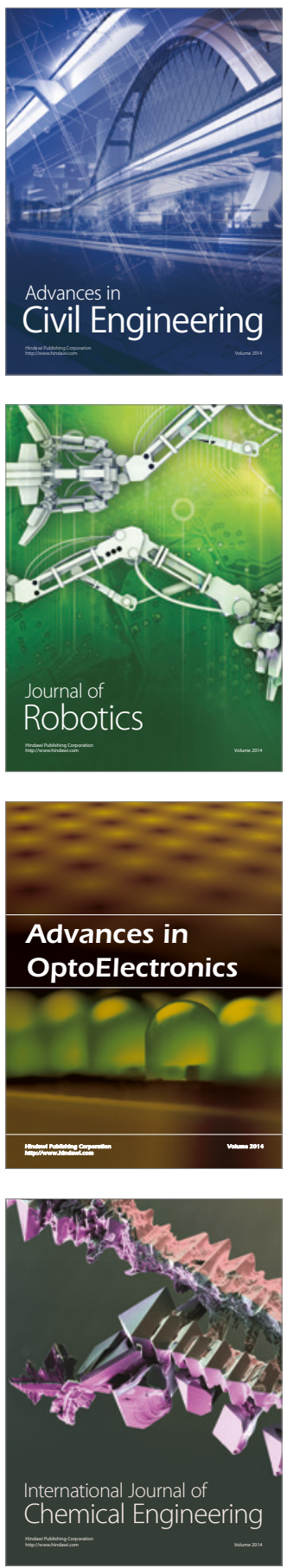

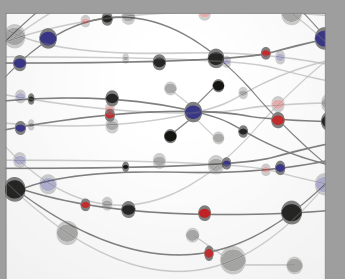

The Scientific World Journal

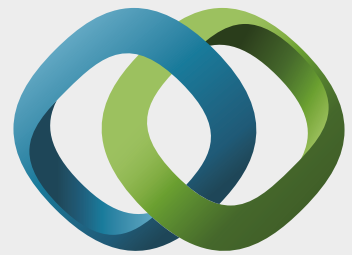

\section{Hindawi}

Submit your manuscripts at

https://www.hindawi.com
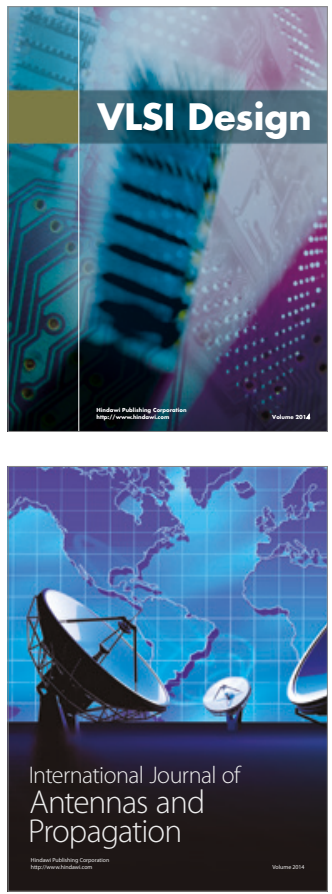

\section{Rotating}

Machinery
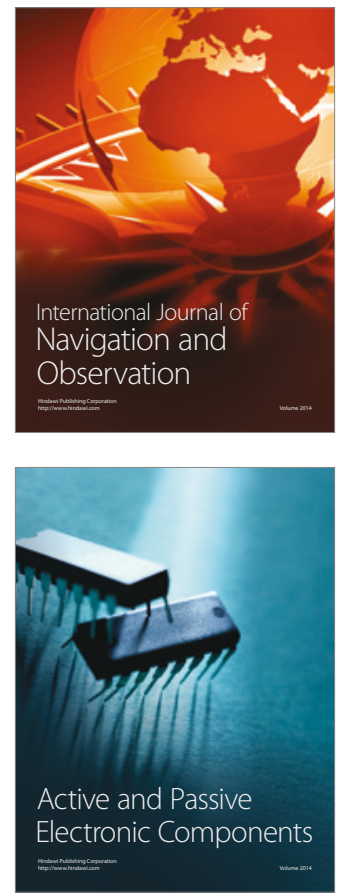
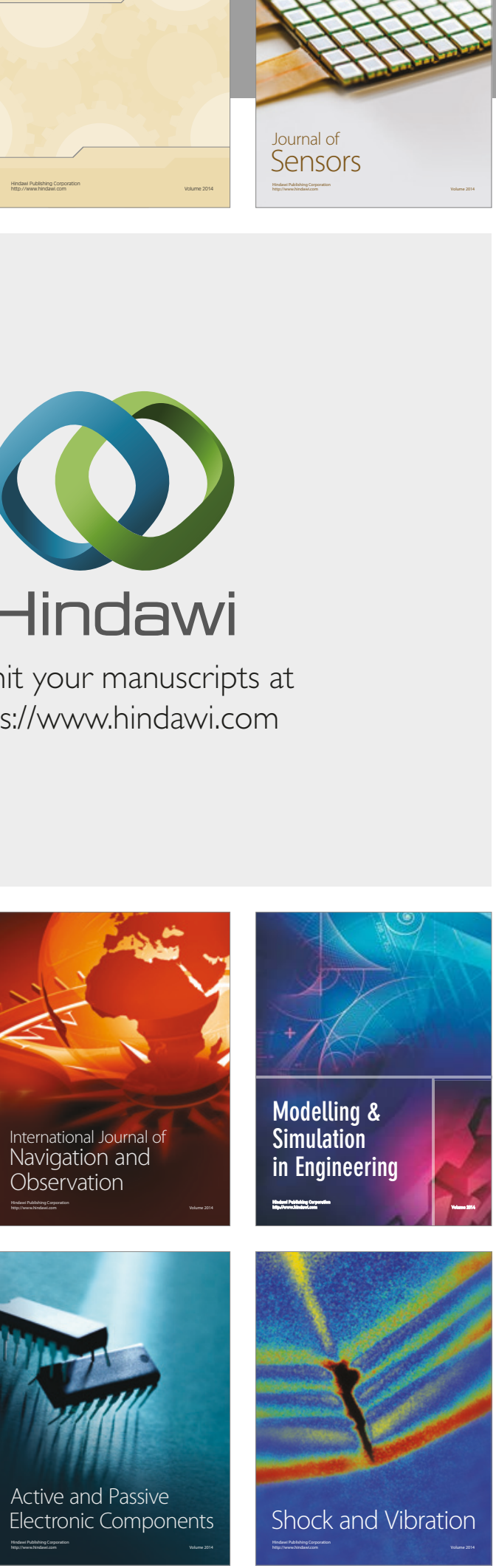
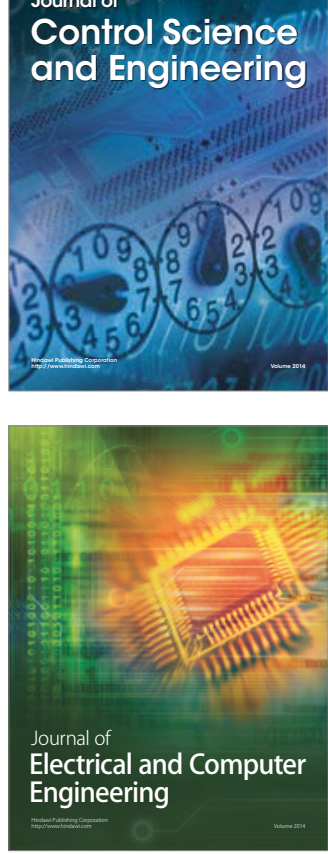

Distributed

Journal of

Control Science

and Engineering
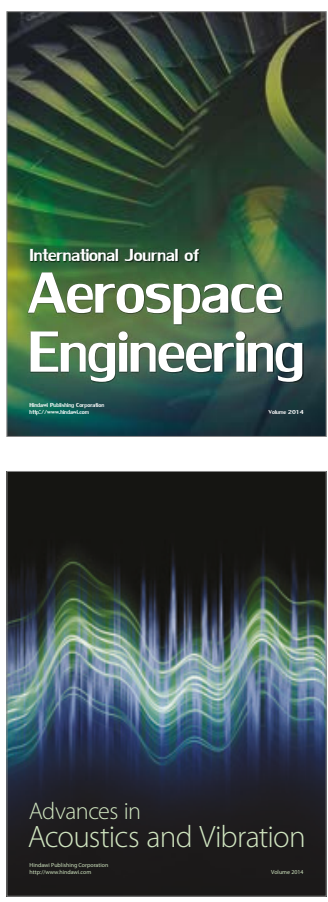

Sensor Networks 